\title{
Dispositivos, gubernamentalidad y educación en tiempos de gerenciamento conservador: un puzle para armar
}

Silvia Grinberg ${ }^{1}$

\section{Resumen}

Las nociones de dispositivo y gubernamentalidad han sido múltiplemente abordadas en las ciencias sociales, ésta última en especial ha sido eje de la pregunta por las transformaciones que desde finales del siglo XX nos han dejado viviendo en una era en que un particular modo del gobierno de sí llama a individuos, sujetos y comunidades a gestionarse y empoderarse, cuya contracara revierte cada vez en la pregunta por quiénes son los incluidos y los excluidos de la promesa de felicidad que trae consigo. Estamos asistiendo a modos donde esas formas del gobierno de sí se enfrentan con el problema del otro; esto es cuál promesa y quiénes son los prometidos. Nuevas lógicas del gobierno de la población asentado en la libertad de hacerse a uno mismo colisionan en sus propias tensiones. No se trata tanto de un giro en la lógica de la gestión de sí, sino de bifurcaciones que encuentran en esa libertad sus límites tanto respecto de las implicancias de ese hacerse como respecto de su control. En este marco de debates proponemos que la noción de dispositivo en su intersección con la de gubernamentalidad constituyen herramientas clave para la problematización del quiénes estamos siendo. Desarrollamos en este artículo un debate conceptual en torno de estas nociones para luego a modo de cierre procurar una aproximación a las dinámicas de nuestra presente era de gerenciamiento-conservador.

Palabras clave: Gubernamentalidad; Dispositivo; Gerenciamiento conservador.

\section{Dispositivos, governamentalidade e educação em tempos de gerenciamento conservador: um quebra-cabeça para montar}

\section{Resumo}

Noções de dispositivo e governamentalidade têm sido abordadas nas ciências sociais, em particular relacionadas às transformações que desde o final do século XX nos deixaram vivendo em uma época na qual um modo particular de conduta conduz os indivíduos e as comunidades a serem geridos e empoderados, cuja contraparte reverte como uma questão de quem está incluído e excluído da promessa de felicidade que ele traz. Estamos testemunhando maneiras pelas quais essas formas de autogoverno enfrentam o problema do outro; qual promessa e quem são os prometidos. Novas lógicas do governo da população baseadas na liberdade de fazer-se a si mesmo colidem em suas próprias tensões. Não é tanto uma mudança na lógica da administração de si mesmo, mas de bifurcações que encontram nessa liberdade seus limites tanto com relação às implicações de que isso é quanto de seu controle. Neste arcabouço de debates, propomos que a noção de dispositivo em sua intersecção com a governamentalidade constitua ferramentas fundamentais para a problematização de quem estamos sendo. Neste artigo, desenvolvemos um debate conceitual em torno dessas noções e, em seguida, como ponto de partida, tentamos abordar a dinâmica de nossa atual era de gestão conservadora.

Palavras-chave: Governamentalidade; Dispositivo; Gerenciamento conservador.

\section{Consideraciones iniciales}

Las nociones de dispositivo y gubernamentalidad han sido múltiplemente abordadas en

\footnotetext{
${ }^{1}$ Laboratorio de Investigación en ciencias Humanas, CONICET/Escuela de Humanidad, UNSAM, Buenos Aires, grinberg.silvia@gmail.com
} 
las ciencias sociales, ésta última, en especial, ha sido eje de la pregunta por las transformaciones que desde finales del siglo XX nos han dejado viviendo en una era en que un particular modo del gobierno de sí llama a individuos, sujetos y comunidades a gestionarse y empoderarse, cuya contracara revierte, cada vez más, en la pregunta por quiénes son los incluidos y los excluidos de la promesa de felicidad (AHMED, 2010) que la gestión de sí trae consigo. Una racionalidad que nos ha ubicado como dignos hacedores de nuestros destinos, gestores de nuestros egos y cuerpos; la estima, el empleo tanto como el aprendizaje o la aptitud devenida fitness, han acogido el prefijo "auto" como deber ser propio de estos tiempos. Asimismo, la era del sí mismo nos ha dejado perplejos ante las alternativas y posibilidades que tenemos de escalar posiciones en los rankings de la autoestima y la realización personal. Ahora, bien, a lo largo de este decenio cada vez más estamos asistiendo a modos donde esas formas del gobierno de sí se enfrentan consigo mismas. El gobierno de la población asentado en la libertad de hacerse a uno mismo colisiona en sus propias tensiones. Gobiernos conservadores y ultraconservadores van ganando las contiendas electorales de modos que desde las postrimerías de la segunda guerra mundial no veíamos ni esperábamos hacerlo. Sin embargo, proponemos aquí que no se trata tanto de una ruptura en las lógicas de la gestión de sí sino de bifurcaciones que encuentran en el llamado a hacerse a uno mismo, el giro de sus límites tanto respecto de sus posibilidades como respecto del control de los impulsos del ego. El giro de la libertad sin contra-pizas no sólo nos enfrenta a la responsabilización y agotamiento que ese trabajo sobre nosotros mismos arrastra - la era del cansancio como la denomina (HAN, 2012)-, sino que nos confronta con la pregunta por las emociones y su control. Esto es la libertad de hacernos a nosotros mismos, el llamado a la realización personal donde lo único que parece interponerse a nuestros propios proyectos somos nosotros mismos y la capacidad de adaptarnos que tengamos, se encuentra que esta máxima no sólo es válida para el Yo, sino también para los otros. En otras palabras en la era yo, el otro vuelve a ser un problema. Así, mientras la gestión de sí sigue siendo clave en las lógicas que asumen el gobierno de la población, donde debemos revisar y adaptar nuestros egos para escalar posiciones en el ranking de la felicidad, por otro lado, esas mismas lógicas asumen un giro conservador.

En este marco de debates en este artículo procuramos dos tareas: en un primer momento ocuparnos de la noción de dispositivo en tanto en su intersección con la de gubernamentalidad 
constituyen una trama clave para la problematización del quiénes estamos siendo. Proponemos para ello un debate conceptual de estas nociones. En un segundo momento, procuramos ensayar una aproximación a las problematizaciones de nuestra presente era donde un particular modo del management deviene conservador. A continuación, entonces, nos adentramos en una discusión conceptual acerca de estas nociones, para luego proponer un debate en torno de las formas del gobierno de la población en la era del management y procurando, asimismo, trazar algunos de los giros de nuestra convulsionada actualidad.

\section{Dispositivos y gubernamentalidad}

Desde fines del siglo XX al compás de la difusión de la obra de Michel Foucault, la noción de dispositivo ha ido ganando espacio en los debates de las ciencias sociales. Los textos y clases de Gilles Deleuze y, algunos decenios más tarde, el texto de Giorgio Agamben han sido clave en esa difusión. En el campo de la educación con derroteros y usos diversos, el concepto de dispositivo tiene $\mathrm{y}$ ha tenido gran impacto, así como significados diversos. Los usos, acentuaciones no dejan de atravesarse mutuamente donde la noción de dispositivo constituye una herramienta conceptual y metodológica para el estudio de nuestra actualidad, de las prácticas en su historicidad, sus reglas y sus modificaciones regulares, las conformaciones y transformaciones. Una actualidad que, como señalara Foucault (1999a), es incontorneable.

Si nos preguntáramos por los aportes de la noción de dispositivo para la investigación podríamos plantear que se trata de una noción que involucra interrogarse por los efectos, las relaciones de poder que no admiten distinciones macro/mico y porque se trata de efectos de poder que involucran tanto lo sedimentado como eso incontrolable que es la actualidad; aspectos todos que aparecen con todas sus fuerzas en cualquier estudio de la cotidianeidad de la vida social. Disponer, organizar y organización, mecanismo o artificio para producir una acción, son algunos de los términos a los que remite el diccionario de la Real Academia. Artificio que nos recuerda que no se trata de mecanismos dados sino creados, producidos con el objeto de disponer. Sin embargo, a diferencia de los muchos y múltiples mecanismos con que podemos encontrarnos en nuestra cotidianeidad (desde ya el artefacto computadora con el cual 
escribimos estas letras) los dispositivos a los que remite Foucault -y nosotros en este texto-, tienen consigo la marca del estar siendo, de las relaciones de poder; esto es de lo incontrolable pero que afecta y es afectado.

\section{¿Qué cosa es un dispositivo?}

El uso o más bien los usos de este concepto en Foucault, como lo describe Castro (2017) encuentran su emergencia

[...] en el curso de los años 1973-1974, en el Collège de France, titulado Le pouvoir psychiatrique. Para ser precisos, no se trata sólo de la noción de dispositivo, sino también de la simple utilización del término. En efecto, éste no aparece, ni siquiera desprovisto de cualquier sentido técnico, antes de la lección del 7 de noviembre de 1973 (CASTRO, 2017, p.14).

En la antesala de vigilar y castigar, en ese curso ofrece una mirada radicalmente diferente a aquella que lo había ocupado en la historia de la locura. Y es en ese marco que refiere al dispositivo de poder como instancia productora de prácticas discursivas. Ello para luego referirse al nivel capilar del poder, la microfísica de los cuerpos, una analítica del poder donde:

[...] lo esencial no es la institución con su regularidad y sus reglas sino justamente esos desequilibrios de poder... Lo importante, entonces, no son las regularidades institucionales sino, mucho más las disposiciones de poder, las redes, las corrientes, los relevos, los puntos de apoyo, las diferencias de potencial que caracterizan una forma de poder y que son, creo precisamente constitutivos a la vez del individuo y de la colectividad. el individuo sólo es, a mi entender, el efecto del poder en cuanto éste es un procedimiento de individualización. Y el individuo, el grupo, la colectividad, la institución aparecen contra el fondo de esa red de poder, $y$ funcionan en sus diferencias de potencial y desvíos (FOUCAULT, 2014, p.32).

Estas afirmaciones Foucault las concluye señalando que es desde allí que para el análisis de nuestra vida social es clave más que preguntarse por las instituciones ocuparse de las relaciones de fuerza, las disposiciones tácticas que atraviesan a las instituciones. Así, si las sedimentaciones caracterizan a las instituciones, o incluso, es lo que más fácilmente vemos en ellas, estas no dejan de ser y hacerse entre ese potencial y sus desvíos, en esas relaciones de 
fuerza. Esto se vuelve un punto clave para la crítica, o para la ontología de nuestro presente, tanto porque corremos el riesgo de perdernos en la analítica de lo sedimentado como porque es en esas luchas o en esos desvíos que se produce la antesala de nuevas sedimentaciones.

Esta mirada tiene varias implicancias conceptuales y metodológicas. En primer lugar, ubica al eje poder/resistencia ya no como dos polos sino más bien como ejercicio o relación entre fuerzas, desequilibrios al decir del autor. Ejercicio, práctica, régimen de prácticas que siempre son históricas e incontrolables. Y éstas son cuestiones centrales. Se trata del doble juego que involucra a los dispositivos: las luchas por la verdad, por el decir veraz de una época, las tecnologías, los programas, planes que se ponen en marcha, así como los haceres y quehaceres, las conductas que a la vez que son conducidas, conducen, afectan y son afectadas. Una mirada, un punto de anclar la mirada donde los sujetos a la vez que somos producidos, ocurrimos en un constante desequilibrio. Hacemos y somos hechos en esa relación de fuerzas a la vez que somos efecto de esa relación. Los puntos de apoyo y los desequilibrios constituyen la clave para una analítica del presente tanto en lo que refiere a las líneas de fuga como a las bifurcaciones propias de una era gerencial que, sin correr el eje de la gestión del ego, involucra modos nuevos de su ejercicio en una revitalizada retórica conservadora.

Seguidamente, retomando a Deleuze y Guattari (2002), todo agenciamiento es individual y social a la vez, políticas y sujetos en su capilaridad. Así, en línea con la noción de pliegue la aparente profundidad de lo humano es menos un sistema psicológico que una superficie discontinua, una multiplicidad de espacios, cavidades, relaciones o divisiones que se establecen a través de una especie de ese pliegue. Esto es formas de experiencia que surgen entre prácticas discursivas y no discursivas. De modo que tanto como pertenecemos a una época y somos hablados, pensados, vestidos y/o habitados por ella también la habitamos y hablamos, pensamos y vestimos. Esto es somos en época y hacemos esa época. En esa línea, señalan Rabinow y Rose (2003) que Foucault refería a las formas detalladas de pensar y actuar que componen nuestro presente, y lo/nos constituyen. Por tanto, si no está de un lado el poder y del otro la resistencia, si aquello que diferencia a los dispositivos es su formación histórica, la posición y las relaciones que se establecen entre elementos, entonces, la crítica de los dispositivos tanto como las luchas son siempre históricas como estratégicas.

Periódico Horizontes - USF - Itatiba, SP - Brasil - e019019 
Los saberes, los enunciados, las verdades de una época sirven para dar cuenta de las diferencias entre configuraciones históricas, pero también para referir a las superposiciones, objetos, significados y discursos. Este es precisamente el rol de la noción de dispositivo en tanto permite acercarse al análisis de las diferentes dimensiones del ejercicio del poder. La multiplicidad de las relaciones de fuerza que son inmanentes al dominio en el que operan y son constitutivas de su organización; el juego por el que operan, las continuas batallas y confrontaciones las transforman, refuerzan e invierten. Como lo resalta Castro (2017) en el curso titulado Théories et institutions penales, Foucault describe el marco general de sus investigaciones como la formación de los saberes ocurre a partir de matrices jurídico-políticas que le dan nacimiento y les sirve de soporte. De forma que no hallamos el conocimiento de un lado y el poder del otro, sino que se trata de formas de "poder-saber" que no se reducen al juego de los intereses ni al de las ideologías.

No es una verdad universal, sino, precisamente, un acontecimiento. $Y$ este acontecer de la verdad es el que tiene lugar, aunque a través de "puntos dispersos". Son esos puntos dispersos aquellos que ofrecen un modo de aproximarse a una particular preponderancia o balance de fuerzas en un tiempo determinado. Esto es a identificar qué conocimientos son puestos en juego y son desarrollados, así como discernir las prácticas de resistencia. Vale aquí retomar lo propuesto por Legg (2011), a la vez que quitarle el sentido de contraposición que propone en su lectura:

mientras Rabinow y Rose (2003), han propuesto que los dispositivos emergen como respuestas a problematizaciones, una de mis mayores inspiraciones detrás de mi problematización es el comentario de Deleuze sobre el trabajo de Foucault en el que destaca que la palabra final en el poder es que la resistencia viene primero (LEGG, 2011, p.128).

Si a esta frase le modificamos el inicial mientras nos encontramos que se trata de la emergencia de modos de ejercicio del poder que involucran, como lo señalara el mismo Foucault, una completa y heterogénea batería de prácticas que se constituyen en modos de problematizar y de responder a esos problemas que no dejan de ser a veces resistencias, otras simplemente conductas que son problematizadas en vistas de producir otras; modos de ejercicio del poder, 
golpes y desagües. En otras palabras, es central la pregunta no tanto por los problemas como por las problematizaciones. Esto es qué es aquello que deviene problema en una determinada época, cuáles son las respuestas a eso que se vuelve tal. Cuestión clave para la interrogación de nuestra actualidad en tiempos en que asistimos a la revitalización de enunciados conservadores como problematización de nuestros presentes.

La analítica de los dispositivos no involucra a un componente en sí, sino a cómo se articulan, ensamblan unos componentes con otros tanto como a sus múltiples desestabilizaciones. Involucra la descripción de aquello que está siendo de un modo muy particular en tanto esa actualidad -eso que está siendo-, supone prácticas sedimentadas, modos estratificados a la vez que bifurcaciones, derivaciones. De manera que la crítica, como radicalización de la pregunta por quiénes somos adquiere notas particulares. Retomamos a Foucault (1996):

[...] hay que considerar la ontología crítica de nosotros mismos no por cierto como una teoría, una doctrina, ni siquiera un cuerpo permanente de saber que se acumula; hay que concebirla como una actitud, un ethos, una vía filosófica donde la crítica de lo que somos es a la vez análisis histórico de los límites que se nos plantean y prueba de su franqueamiento posible (FOUCAULT, 1996, p.111).

De manera que la historicidad de las prácticas no sólo remite al ejercicio del poder sino también a la crítica de su ejercicio. Es en este sentido que proponemos que la noción de dispositivo constituye un concepto metodológico. Acercarse al estudio de nuestra contemporaneidad a través de la noción de dispositivo se constituye en un camino para "tocar" eso que está siendo, relaciones estratificadas, modos de pensamiento sedimentados, leyes, normas, modos de ser, deseos, pero también aquello que se vuelve problema, las voces habilitadas para hablar sobre ellos, los diagnósticos y sus respuestas.

\section{La gubernamentalidad y el dispositivo}

La noción de dispositivo Foucault la desarrolla un poco antes de referir al proceso de gubernamentalización del estado en Seguridad, territorio y población. Asimismo, es en el curso 
nacimiento de la biopolítica donde uno se vuelve adjetivo del otro: como lo apunta Castro (2017), la crisis general del dispositivo de gubernamentalidad según se introdujo en el XVIII es el eje de ese curso donde se ocupa del modo en que se experimenta, practica y se formula esa crisis (FOUCAULT, 2007). La gubernamentalidad, de hecho es un modo de problematizar y responder a esas cuestiones. El gobierno de la población aparece en la escena como parte de las revueltas urbanas y la sucesión de crisis que atraviesa nuestra actualidad no deja de ser parte de esos procesos. Más adelante nos ocupamos de esta cuestión, aquí importa la compleja y mutuamente hablada forma en que la noción de dispositivo y gubernamentalidad se desarrollan entre sí:

En Sécurité, territoire, population, precisamente para describir el funcionamiento de los dispositivos reguladores de la vida de la población, Foucault introduce la noción de dispositivos de seguridad y lo hace contraponiéndolos, por un lado, a los dispositivos de soberanía y, por otro, a los disciplinarios. El primero se encuentra Naissance de la biopolitique, hacia el final de la lección del 24 de enero de 1974. Aquí, Foucault habla de 'dispositivo de gubernamentalidad' (NB: 72) para referirse a la racionalidad gubernamental del liberalismo, entendida como gestión de la libertad, del riesgo y del peligro. El segundo pertenece a L'heméneutique du sujet, a propósito de la contraposición entre las formas de subjetivación de la Antigüedad y la nuestra y también de las relaciones entre el sujeto y la verdad. Al respecto, sostiene Foucault, [...] la historia de las relaciones entre sujeto y verdad debería tratar de reencontrar la muy lenta transformación de un dispositivo de subjetividad, definido por la espiritualidad del saber y la práctica de la verdad por parte del sujeto, en este otro dispositivo de subjetividad que es el nuestro y que, me parece, está organizado en torno a la cuestión del conocimiento que el sujeto tiene de sí mismo y la obediencia del sujeto a la ley (HS: 305) (CASTRO, 2017, p.14).

Dispositivo, gubernamentalidad y subjetividad se entrelazan en sus trabajos desde que, como lo señalara en el poder psiquiátrico, se aleja de cualquier análisis que lo deje del lado de las representaciones, percepciones o mentalidades. El dispositivo es la herramienta conceptual que le permite a Foucault, articular la analítica del poder e incluso acercarse a la materialidad del poder, su ejercicio directo o indirecto sobre los cuerpos; aquello que llamó la (micro)física. El dispositivo como instancia productora de prácticas en el nivel capilar, sus puntos dispersos de aplicación que afectan directamente al individuo, los modos en que nos pensamos y somos pensados, actuados y experienciados.

El dispositivo refiere al ensamblaje de prácticas discursivas y no discursivas que, en tanto

Periódico Horizontes - USF - Itatiba, SP - Brasil - e019019 
tales, configuran las superficies en las que nos inscribimos como sujetos, producimos y somos producidos. Un territorio de inscripciones múltiples, un campo de relaciones de fuerzas. Es una noción que involucra la idea de formación histórica, la red de relaciones que no constituyen ninguno de estos elementos en particular, donde lo central resulta ser el modo "en que hace entrar en resonancia la heterogeneidad de elementos que lo componen de acuerdo con una función y unos objetivos específicos" (CASTRO-GÓMEZ, 2010, p.64). El énfasis, así, radica en la serie de elementos, las conexiones que se establecen entre ellos, los elementos que no necesariamente tienen cosas en común más que el problema y las redes que se establecen entre ellos. Los puntos dispersos a los que referíamos anteriormente.

Seguidamente, la noción de gubernamentalidad fue creada por Foucault para referir a ese momento particular de la historia en el que ocurre la gubernamentalización del estado. Vivimos en la era de la gubernamentalidad descubierta en el siglo XVIII que el autor describe como un fenómeno particularmente retorcido que mientras permitió la supervivencia del Estado, "[...] es a la vez interior y exterior a él, porque son las tácticas de gobierno las que permiten definir lo que debe y no debe estar en la órbita del Estado, lo que es público y lo que es privado, lo que es estatal y lo que no lo es" (FOUCAULT, 2006, p.137). La pregunta por el gobierno o más bien la gubernamentalidad, como señala Braun (2014), se configura como un ensamble ad hoc donde,

historicidad y contingencia se convierten en modos de acercarse a comprender cómo la vida 'administrada' y 'gerenciada' se introduce en los más diversos aspectos de la vida como prácticas fragmentarias y contingentes en respuesta a un mundo que se señala debe ser dinámico y cambiante (p.52).

La analítica de la gubernamentalidad, entonces, radica en el énfasis que se pone en el conjunto de elementos que se ensamblan como en las conexiones establecidas entre ellos y los dispositivos en relación con un conjunto de elementos que configuran los problemas percibidos como las tecnologías que se ponen en juego para ofrecer soluciones. Entre unos y otros, los problemas y las problematizaciones, así como las tecnologías, están los sujetos que hacen y deshacen. Como señala Deleuze las prácticas sedimentadas, pero también las líneas de actualización, los sujetos, la capacidad de afectar y ser afectado, los múltiples haceres.

Periódico Horizontes - USF - Itatiba, SP - Brasil - e019019 
El gobierno no sólo existe como un diagrama cambiante y desigual de poder (GIDWANI, 2009). Ese diagrama surge como una especie de reflexión posterior. Antes que nada, funciona como respuesta frente a aquello que se percibe como problema y reactiva las relaciones de fuerza que ya existen procurando dirigirlas e intervenir en ellas tanto con el objeto de desarrollarlas en direcciones particulares como de bloquearlas (Braun, 2014). Así, retomando la (no) disyunción que planteábamos a partir de Legg (2011) problemas, problematizaciones, respuestas a esos problemas que se configuran en tanto que prácticas de poder que sedimentan mientras también son contestadas. Este es el carácter dinámico que involucra la noción de dispositivo. Mientras que por un lado podemos juzgarlo, darle nombre y definirlo en su modo histórico como dispositivo de sexualidad, de seguridad o gerencial, por el otro involucra las fugas y los desagües, así como las redistribuciones. Ahora, ello no supone que no se produzcan cristalizaciones, prácticas que actúan dirigiendo otras prácticas; en suma, diagramas de poder, campo móvil de fuerzas.

La gubernamentalidad como los dispositivos están lejos de ser un sistema único de gestión con una racionalidad homogénea. Más bien se trata de un conjunto diverso de saberes, prácticas e instituciones que no tienen más unidad ni necesidad que aquella que ocurre en la lucha cotidiana, en la historia. Es, en esa línea que Deleuze define a la noción de dispositivo como "un conjunto multilineal, compuesto de líneas, cada una de las cuales tiene una naturaleza diferente sujeta a cambios de dirección, bifurcación y bifurcado y sujeto a la deriva" (DELEUZE, 1988, p.159). Al considerar

\footnotetext{
las múltiples relaciones de fuerza que se forman y operan en los dispositivos», escribe sobre una 'línea general de fuerza que atraviesa las batallas locales y las une'. Si su aproximación genealógica a la historia es una que empatiza los continuos cambios en instituciones y conceptos, el dispositivo es un desarrollo conceptual que le permite elucidar eso. Le permite evaluar un campo movible de continuidades basadas en ese continuo cambio (BUSSOLINI, 2010, p.88).
}

Si los dispositivos configuran algo que pudiera pensarse como totalidad se trata de una descentrada, ad hoc en su formación. Así, por ejemplo, cuando en la voluntad de saber, Foucault refiere al dispositivo de sexualidad no remite a un fenómeno natural, a fenómenos preexistentes, sino que es el nombre que otorga a una formación cuya definición clave es que es histórica, esto es:

Periódico Horizontes - USF - Itatiba, SP - Brasil - e019019 


\section{HSE}

DOI: https://doi.org/10.24933/horizontes.v37i0.768

no una realidad por debajo en la que se ejercerían difíciles apresamientos, sino una gran red superficial donde la estimulación de los cuerpos, la intensificación de los placeres, la incitación al discurso, la formación de conocimientos, el refuerzo de los controles y las resistencias se encadenan unos con otros según grandes estrategias de saber y de poder (FOUCAULT, 1999b., p.129).

El dispositivo de sexualidad involucra una conformación propia de unas relaciones de poder sobre las que cabe la pregunta sobre sus continuidades y rupturas. Esto es, el quiénes estamos siendo del siglo XXI debe vérselas con las prácticas sedimentadas y cristalizadas producidas en el siglo XIX, contestadas, refutadas, resistidas y reconfiguradas en nuestra contemporaneidad. La analítica de la actual revitalización conservadora requiere ocuparse de esas luchas.

En este marco esta acepción de dispositivo se aleja de cualquier idea de planificación, diseño o premeditación; también del fondo detrás del telón. Se trata de una gran red superficial, estrategias de saber y de poder que se encadenan, se ensamblan. El dispositivo se configura en el diagrama histórico del devenir, como problematización y respuestas (en punga) al quiénes somos que no es ni romántica ni humanista. En lugar de eso, se trata del intento de desarrollar una analítica que haga visible los vectores que dan forma a la relación que establecemos con nosotros mismos, así como a la crítica de nuestra, per se, incontrolable actualidad. Es en esa pequeña brecha, como señalan Rabinow y Rose (2003),

que se abre cuando se pasa de la pregunta '¿en qué tipo de sujetos nos hemos convertido?' [a] cómo nos relacionamos con nosotros mismos como sujetos de cierto tipo", es ahí, en esta epistemología de la relación que se inserta la historia. No en nuestra psique sino en ese pensamiento silencioso que habita los aspectos más íntimos de nuestra experiencia de nosotros mismos (p.14).

Es en ese punto que el estar siendo es el tiempo verbal clave de esta ontología de nosotros mismos y más aún de la analítica de los dispositivos.

\section{Gerenciamiento conservador y educación: las tensiones del control}

Es en el artículo en que Deleuze trabajó sobre la noción de dispositivo donde refiere al

Periódico Horizontes - USF - Itatiba, SP - Brasil - e019019 
proceso de transformación de los modos de ejercicio del poder donde la disciplina descripta por Foucault señala:

conforman la historia, aquello que poco a poco dejamos de ser, y nuestra actualidad se dibuja en disposiciones de control abierto y continuo, disposiciones muy diferentes de las recientes disciplinas cerradas. Foucault está de acuerdo con Burroughs, quien anuncia nuestro futuro controlado antes que disciplinado (DELEUZE, 1995, p.160).

Esta apuesta de Deleuze encuentra dos grandes fuentes, por un lado, los cursos que Foucault (2007) dictó en el College de France publicados bajo el título Nacimiento de la Biopolítica donde, como señalábamos más arriba, refiere a la crisis del dispositivo de gubernamentalidad y otra la idea de control que retoma de Burroughs. Es en ese marco que escribirá luego su postcriptum a las sociedades de control.

Se trata de fuentes clave para la crítica de nuestra actualidad, sus problematizaciones y los dispositivos de poder en los que estamos siendo y haciendo. En primer lugar, Foucault (2007) denomina sociedad de empresa a esa configuración de la vida social que señala está en ciernes y cuyos enunciados remontan al periodo de entreguerras. La sociedad de empresa propone desplaza el centro de gravedad de la acción gubernamental hacia abajo. Asentada en la fobia del estado y la teoría del capital humano que lleva el dominio económico hacia ámbitos inéditos, así como a la definición del individuo que pasa a pensarse como empresario de sí. La noción de sociedad de empresa a pesar de su formulación no remite sólo al mundo de la producción, así como tampoco se trata de la racionalidad del mundo de la economía que se expande hacia otras esferas, mirada que sería más bien cercana a una lectura weberiana de la cuestión.

Como señalamos la gubernamentalidad refiere al arte de gobernar y atraviesa muy diversos ámbitos de la vida y que desplazado hacia abajo, o, más bien promediando el segundo decenio del siglo XXI deberíamos decir estallado en todas las direcciones. Desplazamientos que en la lógica de la sociedad red no tiene un centro sino epicentros múltiples porque es el sí mismo quien deviene nodo de las artes de gobierno contemporáneas. Probablemente, ello es lo que pone en crisis al legado del hacerse a uno mismo de nuestro presente. La cuestión del control se re-escenifica en una sociedad que mientras nos llama a hacernos debe enfrentar que ese llamado 
involucra un todos, una pluralidad de voces que no está muy dispuesta a aceptar, o, para decirlo en los términos de época a tolerar.

La referencia al control que realizara Burroughs en una entrevista radial que le hicieran en 1961 ofrece una pista clave en este debate:

Ginsberg: ¿Qué pasa con el control?

William Burroughs: Ahora todos los políticos asumen una necesidad de control, el más eficiente, el mejor. Todas las organizaciones políticas tienden a funcionar como una máquina, para eliminar el factor impredecible: el afecto-emoción. Cualquier máquina tiende a absorber, eliminar el afecto. Sin embargo, la única persona que puede poner en movimiento a una máquina es alguien que tiene un motivo, que tiene efecto. Si todos los individuos fueran acondicionados según la eficiencia de las máquinas tendría que haber al menos una persona por fuera para dar las órdenes necesarias (GINSBERG; CORSO, 1961, s/n).

Esta imagen del control, o más aun del problema del control, ha sido tematizada en las múltiples literaturas de ciencia ficción, así como en las que llegaron a Hollywood. Por nombrar una de las tantas sagas de este género la muy afamada Matrix se instala allí: la máquina que absorbe la energía y actúa de manera directa sobre la emoción se enfrenta con su propia fuga. Es probable, que cada vez más sea ese factor impredecible hacia donde se desplaza el gobierno hacia el afecto-emoción al que refiere Burroughs. Un centro de gravedad del gobierno que asentado en el Yo, en las multifocales tecnologías del "auto (hacerse/conocerse/aprender/etc. etc.)", habilita el control de aquello que por definición es impredecible y que muta de un modo muy especial los términos del arte gobernar. Unas artes que encuentra en los saberes y tecnologías propias del managment la posibilidad de aprehender a, través de los hilos delgados de la gestión, las prácticas de sí que se conforman entre la autoayuda, el coaching o la programación neurolingüística. El new public managment sin duda ha sido la piedra angular de estas prácticas donde la regulación de las conductas actúa en ese lugar de la emoción-afecto y ocupa un lugar clave en los actuales modos de gobierno. Eso que como supo señalar Burroughs, por definición, está fuera de control, se ha vuelto un aspecto intrínseco de nuestro presente "la capacidad de afectar produce un efecto económico con más rapidez y seguridad que la economía misma y significa que el afecto es una condición real... como la infraestructura para una fábrica" (MASSUMI, 2002, p.45). Sin duda, la red de redes y más aun las redes sociales de esa red poseen 
una capilaridad inusitada. Se trata de tecnologías que actúan al nivel íntimo de la subjetividad y que se dirigen del mismo modo a la intimidad de las instituciones.

Si el control remite a una obsesión, como señalara Burroghs en esa entrevista, y la sociedad de empresa remite al punto donde el capital revierte sobre la subjetividad, son las narrativas de la gestión, del management aquellas que se convierten en zona de contacto de saberes y prácticas muy diversas e incluso encontradas. Unas ya no tan nuevas tecnologías de la administración que adquirieron amplia difusión en las prácticas gerenciales que actúan buscando,

programar estratégicamente las actividades y los comportamientos de los individuos; se trata en última instancia de un tipo de gubernamentalidad que busca programarlos y controlarlos en sus formas de actuar, de sentir, de pensar y de situarse ante sí mismos, de la vida que llevan y del mundo en que viven, a través de determinados procesos y políticas de subjetivación, prácticas y saberes psicológicos orientados a la gestión y dinámica de grupos y de organizaciones, la propaganda, publicidad, marketing, branding, literatura de autoayuda, etc. (GADELHA, 2009, p.178).

Es en esta escena que los dispositivos gerenciales han articulado prácticas de saber y poder donde el gobierno de la población dejó de pensarse como construcción de un universal o totalidad alguna. Esto es, ya no se trata de una sociedad que pensada como cuerpo se espera funcione como totalidad orgánica y, por tanto, las acciones de gobierno o de la educación deberían tender hacia ese ideal que con tanta claridad definió Durkheim. No se trata de homogeneizar poblaciones; el relato del gobierno se construye como su opuesto, como tolerancia de la diversidad, como glorificación del Yo y sus potencias individuales. Así, en la lógica del management una racionalidad de fragmentos define los términos del arte de gobernar que se presenta en la forma del no relato. Si esto es válido en general la educación se vuelve un punto de anclaje muy especial en tanto, así como fue una institución central en los procesos de normalización, en el presente se constituye en espacio clave en el que los sujetos son llamados a hacerse y auto-hacerse. Las pedagogías psi (SILVA, 1999), las pedagogías constructivistas (POPKEWITZ, 1996), pedagogías de las competencias (GRINBERG, 2008), o, en otras palabras, la configuración de las pedagogías al calor de la configuración de la sociedad de aprendizaje (BIESTA, 2005; SIMMONS \& MASCHELEIM, 2008; POPKEWITZ, OLSON, PETTERSON; 2006) 
guardan el hilo común de la individualización de los aprendizajes; de una gesta de la enseñanza que consiste en devenir coach de los alumnos y sus procesos.

En esas dinámicas discurren gran parte de nuestros egos llamados a forjarse el propio destino, a hacerse y auto hacerse. Vivimos en tiempos en que el único límite que podemos aceptar refiere a aquello que podamos/queramos ser, en suma, en tiempos del tú puedes. El límite de aquí en mas lo impone la capacidad, el quantum de empoderamiento que habremos conseguido producir en nuestros egos. Un tsunami de textos de auto ayuda, de nuevos modos de gestión (O’MALLEY, 2009), que nos explican y enseñan cómo vivir mejor. Tsunami que, en el campo de la educación, se articularon en torno de los proyectos institucionales de la gestión eficaz como tecnología de gobierno que arroja responsabilidades y fracasos a las escuelas e individuos (GRINBERG, 2008). Se trata de fabricarnos en un mundo de incertidumbres, devenir, como señaló Foucault (2007), empresarios de nosotros mismos, de movilizar la potencia de la indivualización (GADELHA, 2013).

Ahora, la compleja trama de relaciones, tensiones y luchas que suponen estos procesos ocurren en una cotidianeidad de la vida de los sujetos y las instituciones que supone eso incontrolable: las luchas, fisuras y contradicciones propias de la experiencia. Aquí, el management consigue articular estas nuevas dinámicas en arte de gobernar que un conjunto de saberes, tecnologías, así como un ethos propio de nuestros tiempos. Y en ese proceso el gobierno de sí, aquel que en algún momento refería a que quien iba a gobernar a los otros debía gobernarse a sí mismo vuelve sobre el ego de un modo particular. El gobierno de sí vuelve recargado de un modo tal que el gobierno de los otros repliega como sobre el Yo (GRINBERG, 2015). Definitivamente, en el siglo XXI el ego, el yo, el self, el sí mismo sufre de una sobrevaloración sin límites cuyos efectos vivimos a diario; sobrecargados de elecciones y ofertas que se abren en la danza de unas posibilidades que se nos presentan abiertas al infinito, just in time.

Señalar que la vida escolar desde fines del siglo XX ha atravesado diversos procesos de reconfiguración es, prácticamente, un hecho que no parece necesitar someterse a interrogación. Sin embargo y más allá de esa constatación la pregunta por los cambios empieza a adquirir lógicas y ribetes particulares cuando se trata de la descripción y comprensión de dinámicas que se producen en y desde diversos niveles y ámbitos de la vida social y política. Es posible interrogar 
los cambios desde las vidas en las pantallas, las TIC, los medios de comunicación, la medicalización, la crisis del fordismo y la configuración de la vida urbana y así podríamos seguir refiriendo a procesos involucrados en las tan escritas crisis de la escolaridad. Pero, también y ello nos dirige al último punto de este artículo, cabe la pregunta por lógicas que como pequeños cuestionamientos primero, y cada vez más de modo programático se instalan en ese control de los afectos cuando la era del yo se encuentra con los otros. Esto es gran parte de las acciones de control de la gestión de sí, operan en las lógicas que relatos como los de la autoayuda nos llaman no sólo a realizarnos sino a monitorearnos, a revisar nuestro accionar y desde allí a responsabilizarnos por lo que hayamos o no conseguido. La analítica de la gestión escolar ha hecho de esto un eje de las políticas: la gestión por resultados es la forma de volver a las prácticas de evaluación sobre el sí mismo. Nociones tales como resiliencia se han vuelto las claves para mostrar el éxito de algunos y no de todos. Ahora, en estas lógicas algo se fugó y de ello nos ocupamos a modo de cierre. Esa capacidad de sí, de sobreponerse, de devenir quiénes queramos ser e, incluso, de devenir exitosos en esta tarea consiguió una amplitud de opciones en la promesa de la felicidad que no deja de ser incontrolable. El otro, la posibilidad infinita de devenir otros, enfrenta se vuelve cada vez más el problema de los límites que la gestión de sí trae consigo.

\section{El control, la norma y la diferencia en tiempos de gerenciamiento conservador}

Vivimos tiempos donde la normalización estallada vuelve como crítica. Los espacios de encierro, la estabilidad de las normas y de la proyección estable y segura de la vida en el tiempo, las certezas y las contradicciones, así como la univocidad respecto de a quién revelarnos cedió en la danza de los proyectos estratégicos. La revisión de sí es parte clave de los relatos de la autoayuda como de las promesas de salvación de las iglesias pentecostales (SEMAN, 2015) y en muchos casos de políticas sobre las que cada vez más es difícil distinguir quién es dios y quién es diablo. De hecho, términos como desigualdad y pobreza se vuelven, con altas cuotas de cinismo, parte de las agendas cotidiana de organismos internacionales ${ }^{2}$ y activan planes de austeridad

\footnotetext{
${ }^{2}$ En el discurso pronunciado por la Sra. Christine Lagarde (Presidenta del Directorio Ejecutivo y Directora Gerente del Fondo Monetario Internacional, ante la Junta de Gobernadores del Fondo, en las deliberaciones anuales conjuntas), remite a la reducción de la desigualdad como eje de las políticas económicas: "Si bien la pobreza y la
} 
siempre en nombre de la gestión eficaz, del pueblo y su bienestar.

Ahora, la noción de dispositivo en Foucault ha aparecido de modos diversos

[...] en la forma de expresiones compuestas y frecuentemente en plural, que pueden organizarse de la siguiente manera: los dispositivos de poder se distinguen en dispositivos de soberanía (p.54) y dispositivos disciplinarios (p.48); estos últimos, a su vez, se ramifican en dispositivo de panóptico (p.79), dispositivos asilares (p.156), dispositivos de cura (p.163), dispositivos de captura (p.301), dispositivo clínico (p.305), dispositivo neurológico (p.305), dispositivo médico (p.305) y dispositivo psiquiátrico (p.305) [...] el punto que aquí es clave todos estos dispositivos disciplinarios son dispositivos normalizadores (p.116) (CASTRO, 2017, p.3).

Tendremos que preguntarnos, entonces, qué ha sido de las crisis de esos dispositivos de normalización en la era del Yo, del multiculturalismo y la diversidad, pero también de sus cuestionamientos conservadores. Esa danza del Yo, esa sociedad que nos llamaba a hacernos en nuestra diferencia se encuentra que no puede tolerar tanta, valga la redundancia, diferencia. Así, en los últimos tiempos vivimos todo tipo sensaciones respecto de los "ideales" de la norma que incluyen tanto la crítica como la nostalgia. Una era en que la diferencia parecía haber ganado felizmente la batalla se enfrenta nuevamente a la nostalgia de la norma.

La crisis de los dispositivos remite a un punto que es clave para el arte de gobernar en nuestra contemporaneidad. Ello tanto porque la normalidad se encuentra demodé, como porque es, justamente, en el trastrocamiento de esas prácticas que el gobierno consigue actuar en los más delgados puntos de contacto de la subjetividad. Devenir normales, pensarnos en el mundo como sujetos normales puede ser incluso motivo de ofensa. Tenemos que hacernos en nuestra diferencia. La diversidad, la innovación, la creación, el cambio, desde hace años, se convirtieron en los términos que definen lo bueno, el deber ser de cualquier horizonte de futuro y, desde ya, de la educación. Aquí, lejos de proponer que estuviésemos fuera de la medición y definición de horizontes de deseabilidad importa delinear las particularidades que ha adquirido este relato del no-relato atendiendo, especialmente, a aquello que se presenta como una escala de modulaciones y posibilidades abiertas al infinito. Pero también y, a modo de cierre, muy

desigualdad entre países han disminuido durante la última generación, la desigualdad de ingreso y riqueza dentro de los países está en aumento. Hoy en día, alrededor de la mitad de la riqueza mundial está en manos del $1 \%$ de la población que más tiene" (2017, p.3-4). 
especialmente la crisis de la diversidad a la que nos estamos enfrentando, cuando la promesa de la felicidad no sólo adquiere modulaciones crueles (BERLANT, 2011), sino que cada vez más esa promesa se dirige a segmentos diferenciados. El otro, lo otro vuelve como amenaza al ego que debe hacerse a sí mismo.

Nos encontramos transitando tiempos de nuevos cambios en las lógicas del gobierno de la población donde enunciados conservadores que parecían confinados a grupos minoritarios se expanden y esparcen de modos que no creíamos posibles luego de Auschwitz. Es en esta línea que Rose (2017, p.16) señala:

se trata de asegurar la libertad dentro de territorios cerrados, estamos viendo la reactivación de los mecanismos centrípetos, enmarcados en términos de 'control'. Se establece un nuevo conjunto de estrategias, que se están reespacializando y circunscribiendo al territorio nacional y buscando conocer y controlar lo más posible de ese espacio. Tal vez ahora no simplemente en términos de normas rígidas y simples distinciones de lo que está permitido y lo que está prohibido, pero en términos de un cierto ancho de banda de libertad. Mientras que, en tiempos anteriores, los mecanismos centrípetos siempre se enfrentaban a los problemas del conocimiento, de cómo conocer a todos, quizás hoy, las cosas son diferentes, al menos en la imaginación de las autoridades. El sueño del conocimiento perfecto de una población que queda en libertad se hace posible con la vigilancia del ciberespacio, el seguimiento no solo a través de cámaras web, sino también a través de operaciones de teléfonos inteligentes, tarjetas de crédito y débito, uso de Twitter, Facebook y similares, creando identidades virtuales para cada uno de nosotros, que puede ser minado por algoritmos, alimentado por la inteligencia de la máquina para buscar patrones conocidos, y luego 'marcados en rojo' por algoritmos para la atención de las autoridades.

Los big data parecen hacer posible el control del que hablara Burroughs (GINSBERG; CORSO, 1961). La cuestión, entonces, ya terminando el segundo decenio del siglo XXI es que esa normalidad estallada, la era de la diversidad y la tolerancia (ZIZEK, 2008) se está encontrando con sus propias tensiones: quién tolera, para quiénes esa tolerancia, pero también de qué es aquello que se está dispuesto a tolerar. Es en esa línea que cabe revisitar la pregunta que se hiciera Stuart Hall (2003) ¿quién precisa identidad? Se trata todas ellas, de tensiones que, al mismo tiempo, en la era del management no pueden resolverse sino en nombre de la libertad. Así el problema de control se topa con una problematización no tan nueva: la seguridad que 
debe garantizarse en aras de nuestra libertad. Foucault se ha ocupado de ello en Seguridad, Territorio y población. No nos ocuparemos de aquí de ello, sin embargo, cabe señalar que si la cuestión de la seguridad permanece como problema seguramente las problematizaciones involucran tanto tecnologías diferentes como luchas y estrategias. Esto es el problema de la seguridad se enfrenta nuevamente con la pregunta por la regulación de los flujos, la circulación de mercancías o las migraciones. En ese texto Foucault (2006) refería a los reclamos de urbanizar el territorio que involucraban la acción de "policiar"3". Si esa imagen vuelve a aparecer, ella se enfrenta con otro eje: en los últimos años la regulación, la seguridad se ve enfrentada a la revitalización o, simplemente, a la fuerza que adquieren los movimientos feministas o étnicos o, más en general, las luchas de los múltiples colectivos diferentes/disidentes que no están dispuestos a ceder su libertad en aras de alguna supuesta seguridad. Nuevamente el otro, lo otro atenta a un nosotros para quienes la promesa de la felicidad y la realización personal ha ido demasiado lejos. Como lo señalamos al principio quiénes son los sujetos merecedores de la promesa de la felicidad, pero también qué felicidad estamos dispuestos a tolerar es parte de lo que está en ciernes. El control del afecto/emoción, como señalaba Burroughs, se encuentra con que alguien por fuera tiene que apretar la máquina.

\section{A modo de cierre: el puzle para armar}

Las nociones de dispositivo y gubernamentalidad múltiplemente visitadas en la obra de Foucault, son puntos de apoyo clave para la inteligibilidad de nuestra convulsionada actualidad. Este artículo procuró adentrarse en esa tradición pero haciendo especial hincapié en la intersección entre ambas nociones a los efectos de procurar una problematización de nuestra actualidad que en la analítica de las fuerzas de quienes somos instale la pregunta por nuestro devenir. Así, y justamente asentados en la clave que estos conceptos involucran no se trató de

\footnotetext{
${ }^{3}$ Sobre esta cuestión amerita un trabajo en sí; valga aquí la siguiente cita para enmarcar la cuestión: "Hay ciudades porque hay policías, señala Foucault, y porque hay ciudades tan perfectamente policiadas, surgió la de trasladar la policía a escala general del reino. 'Policiar', 'urbanizar': me limito a evocar estas dos palabras para que vean todas las connotaciones, todos los fenómenos de eco que puede haber en ellas; a pesar de todos los desplazamientos de sentido y las atenuaciones que pude haber en el transcurso del siglo XVII, policiar y urbanizar son la misma cosa" (2006, p.385).
} 
encontrar la continuidad de antiguas relaciones de fuerza donde pareciera que la historia está destinada a repetirse sino, más bien en la analítica de esas fuerzas procurar los puntos de apoyo de las actuales luchas y sus emergencias. Resuena aquí nuevamente que no se trata de ideologías e intereses sino del saber-poder, de los puntos dispersos que se ensamblan y pujan. Es en estas lógicas que mientras que a veces parece que nuestras sociedades han conseguido fugar de la norma y la disciplina, otras nos encontramos frente a movimientos donde nos vemos enfrentados a preguntarnos si no están volviendo recargadas. Sin embargo, si apoyamos metodológicamente la interrogación a través de esas nociones los equilibrios y sedimentaciones, pero también sus desequilibrios hacen al eje de la crítica de las lógicas que alcanza el gobierno de la población en una determinada época.

Vivimos tiempos en que las lógicas de la sociedad de empresa asentadas en unas aggiornadas tecnologías del Yo, se ven enfrentada en sus propias tensiones. Por un lado, nos encontramos con que el gobierno de sí en tanto que modulación clave del gobierno de los otros se configura como dispositivos del ego donde se acoplan líneas y series muy diversas que encuentran en la gestión de sí, al afecto como sujeto y objeto, o, retomando la clásica definición foucaultiana, el afecto devino blanco y objeto de poder. Ello tanto a nivel de los individuos como de las instituciones; revisión, monitoreo y gestión son las claves de una era donde la responsabilidad recae siempre en el ego. Es entre esas mismas fuerzas que el ego que no deja de fugar y se vuelve lugar de clivaje del control. En otras palabras, son esas tecnologías las que han tenido un lugar central en la revuelta de la identidad y la configuración de subjetividades emergentes. Ahora, como lo señalara Guattari (2008) "todos los sistemas políticos tropiezan hoy en día, en grados diversos, con los problemas de la identidad subjetiva" (53); es, justamente, sobre esa revuelta que se instala la actual tormenta conservadora que no eyecta la gestión del ego sino que por el contrario es sobre esas tecnologías que opera.

No hay nada que ver detrás del telón, señalaba Deleuze (1994) en lógica del sentido, "es que lo visible, o más bien toda la ciencia posible está a lo largo del telón, que basta con seguir lo bastante lejos y lo bastante estrechamente, lo bastante superficialmente, para invertir lo derecho, para hacer que la derecha se vuelva izquierda e inversamente" (p.33). Y es aquí donde la idea del puzle adquiere especial vigor conceptual y metodológico. No se trata de encontrar lo 
que queda detrás del escenario sino de operar a través de una analítica que se ocupe de los saberes, los puntos dispersos del ejercicio del poder, los lugares de apoyo y de clivaje siempre móviles, incontorneables. Un puzle, en suma, al que siempre le va a faltar una pieza.

\section{References}

AHMED, S The promise of happiness. Durham and London: Duke University Press, 2010.

BERLANT, L. Cruel optimism. Durham: Duke University Press, 2011.

BIESTA, G. Against learning: reclaiming a language for education in an age of learning. Nordisk Pedagogik, Oslo, v.25, p.54-66, 2005.

BRAUN, B. P. A new urban dispositif? governing life in an age of climate change. Environment and Planning D: Society and Space, v.32, n.1, p.49-64, 2014. Disponível em: https://doi.org/10.1068/d4313.

BUSSOLINI, J. What is a Dispositive? Foucault studies, n.10, p.85-107, 2010.

CASTRO, E. Los dispositivos foucaultianos. Fermentario, v.2, n.11, 2017 p.1-19.

CASTRO-GÓMEZ, S. Historia de la gubernamentalidad: razón de estado, liberalismo y neoliberalismo en Michel Foucault. Bogotá: Siglo de Hombre Editores, 2010.

DELEUZE, G.; GUATTARI, F. Mil mesetas: capitalismo y esquizofrenia. Valencia: Pre-textos, 2002.

DELEUZE, G. Qué es un dispositivo? In: Michel Foucault filósofo, Barcelona, Gedisa, 1988.

DELEUZE, G. Lógica del sentido. Barcelona: Paidós, 1994.

DELEUZE, G. Post-scriptum sobre las sociedades del control. In: Deleuze G. Conversaciones 1972-1990. Valencia: Pre-Textos, 1995.

FOUCAULT, M. ¿Qué es la ilustración? Córdoba, Argentina: Alción editora, 1996.

FOUCAULT, M. La arqueología del saber. Argentina: Siglo XXI, 1999a.

FOUCAULT, M. Historia de la sexualidad. Argentina: Siglo XXI, 1999b.

FOUCAULT, M. Seguridad, territorio y población. Argentina: Fondo de Cultura Económica, 2006.

FOUCAULT, M. Nacimiento de la biopolítica. Argentina: Fondo de Cultura Económica, 2007. 
FOUCAULT, M. El poder psiquiátrico. Argentina: Fondo de Cultura Económica, 2014.

GADELHA, S. Governamentalidade neoliberal, teoria do capital humano e empreendedorismo. Educação \& Realidade, v.34, n.2, p.171-186, mai/ago, 2009.

GADELHA, S. Empresariamiento de la sociedad y el gobierno de la infancia pobre. Revista Colombiana de Educación, Bogotá, Colombia, n.65, p.215-223, 2013.

GIDWANI, V. Subalternity. In: KITCHIN, R; THRIFT, N. (Org.) International Encyclopedia of Human Geography, v.11, Oxford: Elsevier, 2009, p.65-71.

GINSBERG, A.; CORSO, G. Interview with William S. Burroughs. Entrevistado: William S. Burroughs. Journal for the Protection of All Beings, s/n, 1961.

GRINBERG, S. Educación y poder en el siglo XXI: gubernamentalidad y pedagogía en las sociedades de gerenciamiento. Buenos Aires: Miño y Dávila, 2008.

GRINBERG, S. El gobierno de sí recargado: educación, pedagogía y gubernamentalidad en las sociedades de gerenciamiento. Textura, v.17, n.34, p.10-31, 2015.

GUATTARI, F. La ciudad subjetiva y post-mediática: la polis reinventada. Fundación Comunidad Cali: Colombia, 2008.

HALL, S. Introducción: ¿quién necesita identidad? In: HALL, S.; DU GAY, P. (Org.). Cuestiones de identidad cultural. Buenos Aires: Amorrortu editores, 2003, p.13-39.

HAN, B-C. La sociedad del cansancio. Barcelona: Herder, 2012.

LAGARDE, CH. Un nuevo panorama económico, un nuevo multilateralismo. Fondo Monetario Internacional: discurso para las Reuniones Anuales de 2018, Bali, 12 de octubre de 2018, disponible en https://www.worldbank.org/content/dam/meetings/external/annualmeeting/GS1803-MDOPENS-Final.pdf. Acesso em: 29 mar. 2019.

LEGG, S. Assemblage/apparatus: using Deleuze and Foucault. Area, v.43, n.2, 128-133, 2011.

MASSUMI, B. Parables for the virtual: movement, affect, sensation. Durham/London: Duke University Press, 2002.

O'MALLEY, P. Resilient subjects: uncertainty, warfare and liberalism. Economy and Society, UK, v.39, n.4, p.488-509, 2009.

POPKEWITZ, T. S. El estado y la administración de la libertad a finales del siglo XX:

Periódico Horizontes - USF - Itatiba, SP - Brasil - e019019 
descentralización y distinciones Estado/sociedad civil. In: PEREYRA, M. A.; MINGUEZ, J. G.; BEAS, M.; GÓMEZ, A. J. (Org.) Globalización y descentralización de los sistemas educativos. Barcelona: Ediciones Pomares, 1996, p.119-168.

POPKEWITZ, T. S.; OLSON, U.; PETTERSON, P. The learning society, the unfinished cosmopolitan, and governing education, public health and crime prevention at the beginning of the twentyfirst centur. Educational Philosophy and Theory, v.38, n.4, p.431-449, 2006.

RABINOW, P.; ROSE, N. S. The essential Foucault: selections from essential works of Foucault, 1954-1984. New York: New Press, 2003.

ROSE, N. Still 'like birds on the wire'? freedom after neoliberalism. Economy and Society, p.303323, 2017. DOI: 10.1080/03085147.2017.1377947.

SEMAN, P. Diferencia y transversalidad en la religiosidad de los sectores populares: mirando con telescopio luego de haber usado el microscópio. Apuntes de Investigación del CECYP, n.18, p.71-107, 2015.

SILVA, T. T. Las pedagogías PSI y el gobierno del yo en nuestros regímenes neoliberales. Archipiélago: cuadernos de crítica de la cultura, España, n.38, p.56-61, 1999.

SIMMONS, M.; MASCHELEIM, J. Our 'will to learn' and the assemblage of a learning apparatus. In: FEJES, A.; NICHOLL, K. (Org.). Foucault and lifelong learning: governing the subject. London: Routledge, 2008, p.48-60.

ZIZEK, S. En defensa de la intolerancia. Sequitur: Madrid, 2008.

Recebido em fevereiro de 2019.

Aprovado em abril de 2019. 